\title{
How Social Are Social Media? A Review of Online Social Behaviour and Connectedness
}

\author{
Tracii Ryan,' Kelly A. Allen, ${ }^{2}$ DeLeon L. Gray ${ }^{3}$ and Dennis M. Mclnerney ${ }^{4}$ \\ 'Faculty of Education, Monash University, Melbourne, Victoria, Australia \\ ${ }^{2}$ The Melbourne Graduate School of Education, The University of Melbourne, Victoria, Australia \\ ${ }^{3}$ College of Education, North Carolina State University, Raleigh, North Carolina, USA \\ ${ }^{4}$ Department of Special Education and Counselling, Education University of Hong Kong, Hong Kong
}

\begin{abstract}
The use of social media is rapidly increasing, and one of the major discussions of the 21 st century revolves around how the use of these applications will impact on the social relationships of users. To contribute to this discussion, we present a brief narrative review highlighting the advantages and disadvantages of social media use on three key aspects of social connectedness: social capital, sense of community, and loneliness. The results indicate that using social media can increase social capital, lead to the formation of friendships and communities, and reduce loneliness. However, some social media site users may experience weakening friendships, online ostracism, and heightened loneliness. Therefore, we argue that the use of social media has contradictory effects on social connectedness. Moreover, the direction of these outcomes is contingent upon who is using the site and how they are using it. Based on these arguments, possible directions for future research are discussed. It is recommended that discourse be continued relating to the association between online social behaviour and connectedness, as this will enable researchers to establish whether the positive outcomes of social media use outweigh the negative.
\end{abstract}

Keywords: social connectedness, social capital, loneliness, sense of community, social media

Social connectedness is 'a short-term experience of belonging and relatedness, based on quantitative and qualitative social appraisals and relationship salience' (van Bel, Smolders, Ijsselsteijn, \& Kort, 2011, p. 2). Establishing a sense of social connectedness is an integral aspect of human life and one that enhances various aspects of psychological wellbeing (McCoy, 1999; Mauss et al., 2011). Individuals are inherently driven to seek and maintain their social ties to others, engaging in behaviours such as joining groups, conversing with strangers, and reaching out to existing acquaintances (Baumeister \& Leary, 1995).

In recent times, social media have become increasingly popular tools for engaging in social behaviour (Hart, 2011; Spiliotopoulos \& Oakley, 2013). Social media are online platforms that allow users to create a profile, connect with other users, and share and exchange content (boyd \& Ellison, 2007; Henderson, Snyder, \& Beale, 2013). There are various forms of social media available, including social networking sites (e.g., Facebook, Instagram, Snapchat), instant messaging services (e.g., What-
sApp, Facebook Messenger), macro- and micro-blogging sites, (e.g., Twitter, WordPress, Tumblr), massively multiplayer online games (e.g., World of Warcraft, League of Legends), and virtual worlds (e.g., Second Life). Social networking sites (SNS) are arguably the most popular forms of social media in use today. For example, statistics from Facebook indicate that this site has in excess of one billion daily users worldwide (Facebook, 2016). Furthermore, a recent report shows that $69 \%$ of Australians use SNS (Sensis, 2016), and 57\% of these do so daily.

With the rapid growth in popularity of social media, the level of engagement in online communication has grown. As such, it is now more likely than ever that the majority of an individual's offline social network can be contacted online. This trend has, no doubt, changed the dynamics of social interaction and may have implications

ADDRESS FOR CORRESPONDENCE: Tracii Ryan, Faculty of Education, Monash University, 29 Ancora Imparo Way, Clayton Campus VIC 3800, Australia. Email: tracii.ryan@monash.edu 
for how the need for social connectedness is established, maintained, or thwarted. Researchers have thus begun to critically examine the relationship between social media use and social connectedness (Ahn \& Shin, 2013; Allen, Ryan, Gray, McInerney, \& Waters, 2014; Grieve, Indian, Witteveen, Tolan, \& Marrington, 2013; Sheldon, Abad, \& Hinsch, 2011).

A limited yet intriguing set of studies indicates that social media users can experience increases in social connectedness (Ahn \& Shin, 2013; Grieve et al., 2013; Sheldon et al., 2011). However, the same studies note that social media use can also undermine social connectedness. These mixed results imply that the outcomes associated with social media use can vary in systematic ways and raise the question of whether the benefits outweigh the potential for harm (Allen et al., 2014). The current article contributes to this growing and important line of work by presenting a brief narrative literature review of studies examining the interplay between social connectedness and social media use.

The overall purpose of a narrative literature review is to present an aggregated and comprehensive overview of the extant literature on a particular topic of interest (Green, Johnson, \& Adams, 2001). Due to the lack of existing research in this area, the present review takes an inductive approach: relevant literature is synthesised, findings are highlighted relating to the beneficial and detrimental social connectedness outcomes that can be traced back to social media use, theories are identified that may be relevant to understanding the relation between these two domains, and suggestions are made to direct future research in this area. As argued by Stebbins (2001), inductive reasoning [is] important in science in part because deductive logic alone can never uncover new ideas and observations' (p. 8). This point is particularly germane in research relating to technology use, as its impact on human behaviour can be difficult to predict.

Within, research findings are reviewed relating to the positive and negative outcomes of social media use on three aspects of social connectedness: social capital, sense of community, and loneliness. These three elements were selected for two reasons. First, scholars have previously established their relevance to social connectedness (Bandiera, Barankay, \& Rasul, 2008; Cornwell, Laumann, \& Schumm, 2008; Malta, 2005; Russell, 1996; van Bel, Smolders, Ijsselsteijn, \& De Kort, 2009). Second, initial literature searches revealed that these were the most commonly examined components of social connectedness.

Social capital refers to the advantages that can be gained through building and maintaining networks of relationships (Putnam, 2000). For example, Coleman (1988) reported that the combination of a supportive family dynamic and a strong school community was associated with the likelihood that a student would graduate from high school. This example demonstrates two distinct levels of social capital: bridging capital and bonding capital. Strong ties such as those found among family members and close friends are known as bonding social capital, while weak ties such as those found within a school community are known as bridging social capital. A third level, maintained capital, has also been suggested by Papacharissi and Mendelson (2011), and describes the advantages associated with preserving ties to members of a previously inhabited community. A common example of this form of social capital is seen when university students maintain friendships with their old high school friends.

Sense of community is the belief that an individual belongs and feels connected to a group in which their needs are considered to be important (Pretty, Conroy, Dugay, Fowler, \& Williams, 1996). Attaining a sense of community can be psychologically rewarding, leading to enhanced life satisfaction and wellbeing (Sum, Mathews, Pourghasem, \& Hughes, 2009). While sense of community is typically conceptualised as an offline phenomenon, individuals can also obtain this feeling in an online context (Blanchard \& Markus, 2004).

The experience of loneliness is associated with the perception of insufficient personal relationships and a lack of social connectedness (Holladay et al., 1997). Importantly, loneliness is not necessarily a function of social rejection; at times it may be a byproduct of personal and situational factors, such as reduced mobility, geographical isolation, or social anxiety.

As some scholars have noted, the unique communicative features of the internet can offer appealing alternatives for lonely individuals that theoretically may enhance their feelings of social connectedness (AmichaiHamburger \& Ben-Artzi, 2003). For instance, individuals who are geographically isolated or who have reduced mobility can communicate easily with friends and family via text messaging, voice, or video calls. Furthermore, specialists claim that for socially anxious individuals who often have difficulty expressing themselves in face-to-face social scenarios (e.g., Caplan, 2006; Lee, Cheung, \& Thadani, 2012, Saunders \& Chester, 2008), the asynchronous or anonymous nature of online communication provides a more comfortable environment for these people to express their true selves and achieve a sense of social disinhibition (Bargh, McKenna, \& Fitzsimons, 2002; Suler, 2005).

\section{Method}

This narrative review was conducted according to guidelines proposed by Green, Johnson, and Adams (2001). Literature searches were performed by two authors (TR and KA) in June 2014, using the following electronic academic databases: Ovid Medline, Mental Health Abstracts, PsycINFO, ProQuest, Social Sciences Abstracts, 
Sociological Abstracts via SocioFile, Academic Search Premier, Social Sciences Citation Index, and ERIC. A combination of search terms were used, including connectedness, social capital, belonging, community, loneliness, social media, social networking, Internet, Twitter, and Facebook. The abstracts of each article returned in the searches were reviewed and the full publications were obtained where possible. Manuscripts that adhered to the following criteria were reviewed: (a) appears in a peer-reviewed journal; (b) published between 2000 and 2014; (c) empirical study; (d) written in English; (e) reports either positive or negative outcomes of social media use on social capital, sense of community, or loneliness.

\section{Findings}

By conducting a streamlined search in this new research domain, 12 studies were identified that met the inclusion criteria: four focused on social capital, four focused on sense of community, and four focused on loneliness. Manuscripts were obtained from 11 different academic journals, and one volume of conference proceedings. The results of these studies are presented in individual subsections, beginning with social capital.

\section{Social Capital}

According to Ellison, Steinfield, and Lampe (2007), social media sites appear to be useful tools to enhance social capital. For example, Facebook was initially designed to allow university students to meet and interact with each other and was structured around the concept of exclusive 'networks'; in order to join Facebook, potential users were required to sign up using an official email account from their academic institution. This allowed users to search Facebook easily for existing offline connections, and facilitated the development of new connections within the educational community.

To ascertain whether the concept of social capital could apply in online settings, Ellison et al. (2007) conducted a study of 800 undergraduate students from the United States. The authors hypothesised that higher levels of Facebook use would be positively associated with bonding, bridging, and maintained social capital. In particular, Ellison et al. argued that maintained social capital would be extremely relevant for university students from the United States who are often expected to move away from their home communities to attend college. The results showed that intensity of Facebook use was positively associated with all three forms of social capital, therefore supporting the researchers' hypotheses. Students revealed that they were using Facebook predominantly to 'keep in touch with old friends and to maintain or intensify relationships characterized by some form of offline connection such as dormitory proximity or a shared class' (Ellison et al., 2007; p. 1162). The researchers also found that, for students with low self-esteem, greater Facebook use was associated with higher levels of bridging social capital. Ellison et al. interpreted this finding by arguing that students could use Facebook as a tool to cement the latent ties that exist in extended offline social networks.

As the design of the study by Ellison et al. (2007) was cross-sectional, the researchers were not able to make any assertions regarding the direction of the relationship between Facebook and the improvements in social capital. However, a follow-up longitudinal study by the same authors showed that the reported gains were a direct result of Facebook use (Steinfield, Ellison, \& Lampe, 2008). It appears then that students with low self-esteem did increase their network of weak ties through the use of Facebook, an outcome that may foster a sense of social connectedness and lead to associated improvements in wellbeing. Taken together, the results from these two studies are encouraging; however, they may have lost relevance due to the fact that they were conducted between 2006 and 2008 (Ellison et al., 2007; Steinfield et al., 2008). Facebook has evolved considerably since this time; for example, it is no longer an exclusive social media platform for university students and does not rely so heavily on the concept of networks.

Due to these changes, a 2011 study by Vitak, Ellison, and Steinfield aimed to determine whether the previous results could be replicated. Using a sample of 325 randomly selected undergraduate students, the researchers measured intensity of Facebook use, as well as bonding and bridging social capital, within the university context. The results revealed that intensity of Facebook use did not predict bonding social capital; however, the relationship between Facebook use and bridging social capital was still apparent. This result partially supports the work of previous scholars, but also may reflect the move away from exclusive networks on Facebook (Ellison et al., 2007; Steinfield et al., 2008). To explain their results, Vitak et al. (2011) argued that the removal of Facebook's exclusive network structure has allowed a 'larger, more heterogeneous pool of users [to] join the site' (p. 8). This, in turn, may have led to a reduction in the intimacy of Facebook relationships and negatively affected the experience of bonding social capital. On the other hand, a larger network of Facebook friends would most likely contain a higher proportion of weak ties, which might lead to an enhancement of bridging social capital.

In support of the conclusions made by Vitak et al. (2011), a 2014 study by Bohn, Buchta, Hornik, and Mair examined the relationship between Facebook use and social capital among 438,851 Facebook users. These researchers found that while adding Facebook friends did increase levels of bonding social capital, this effect was reduced in users with more than 600 friends. In addition, Facebook users posting more frequently than once every 10 days had lower levels of bonding social capital. Conversely, levels of bridging social capital appeared to 
increase with more frequent postings (up to seven per day). These results are consistent with the studies discussed above and imply that regular SNS activity can increase individuals' network of weak ties. On the other hand, intense SNS use appears to have negligible effects on closer relationships.

\section{Sense of Community}

Limited research has looked specifically at whether social media use helps or hinders the development of online sense of community, and of the few studies that do exist, the results tend to be mixed. Some research has identified that social media use leads to enhanced feelings of community. For example, Gruzd, Wellman, and Takhteyev (2011) found that a personal community existed on Twitter through the maintenance and creation of new social connections. The authors observed that a sense of belonging, constant communication, formation of social connections, and a sense of interpersonal commitment were present in the Twitter community. Other research has reported more neutral results; using data from 133 college students, Reich (2010) assessed whether young adults feel a sense of community within their MySpace and Facebook networks. Despite references towards social media as online communities, Reich found that users of these sites tended to employ them to communicate with other individuals rather than to establish a sense of community.

While the act of communicating via social media does not necessarily imply that an individual is intentionally trying to establish a sense of community, results of empirical studies suggest that being ignored by other social media users can negatively impact feelings of community. In fact, the term cyberostracism was coined by Williams, Cheung, and Choi (2000) to describe the phenomenon that occurs when internet users feel excluded or perceive a lack of feedback from online community members. In a study of 1,486 internet users from 62 countries, Williams et al. found that cyberostracism occurred in an interactive online game setting, even when the other players were completely unknown to the participant. Ostracised participants experienced a decline in belonging, control, and positive affect.

An Australian study by Tobin, Vanman, Verreynne, and Saeri (2015) reported similar results in relation to Facebook use. The researchers recruited 79 undergraduate students and asked them to enter a computer laboratory in groups of 3-7. Students were asked to create a new Facebook account for the purpose of the study and to post a status update about an interesting recent occurrence. They were also asked to read the status updates of other students in their group, and comment on updates that interested them. The results indicated that students who posted a status update and received no comments from other students felt less included in the group and had lower levels of belonging. Such findings suggest that a reduction in online sense of community through the experience of cyberostracism is yet another potential drawback of social media use.

\section{Loneliness}

When looking at the research relating to loneliness and social media use, it is clear that online social behaviour can lead to positive outcomes. Große Deters and Mehl (2013) conducted an experimental study in which two groups of undergraduate students were asked to either post more frequent status updates than usual $(n=37)$ or continue using Facebook as they normally would $(n=49)$. The authors discovered that students who posted more frequent status updates had reduced levels of loneliness and that this effect was due to an enhanced feeling of connectedness. In support of these results, another study reported that frequent Facebook use decreased loneliness among a sample of 340 first-year university students (Lou, Yan, Nickerson, \& McMorris, 2012).

Alternatively, other researchers have reported that social media use can increase loneliness. For example, a study of 754 U.S. adults by Stepanikova, Nie, and He (2010) found that people who spent a lot of time communicating online (e.g., using chat rooms, SNS, and instant messenger) felt lonelier than those who spent less time or no time at all online. In contrast to the positive outcomes reported earlier, time expended using the internet was positively correlated with loneliness and negatively correlated with life satisfaction. Such results led the authors to postulate that engaging in social activity online is essentially a solitary activity that may reduce the positive benefits of social interaction. In support of this assumption, Turkle (2011) argues that connecting with people over the internet only gives us the perception of friendship; even though we are in contact, we still remain physically alone.

A study relating to social media use among socially anxious individuals revealed that adolescents who communicated on Facebook to compensate for their offline social skill deficits actually increased their levels of loneliness (Teppers, Luyckx, Klimstra, \& Goossens, 2014). The same study also demonstrated that adolescents who used Facebook to augment their offline social networks (i.e., by finding new friends) experienced reduced loneliness. Overall, these results imply that the experience of reducing or increasing loneliness through social media use may be related to the motives behind usage, and the characteristics of individuals using the site.

\section{Discussion}

This article presents a brief narrative literature review exploring mixed research findings relating to social media use and three aspects of social connectedness: social capital, sense of community, and loneliness. The 
benefits related to fostering social connections through social media use were evident in empirical findings that demonstrate increases in social capital (Ellison et al., 2007; Steinfield et al., 2008), attainment of a sense of community (Gruzd et al., 2011), and reduction of loneliness (Große Deters \& Mehl, 2013; Lou et al., 2012). The negative outcomes became apparent when looking at how high levels of social media use reduces bonding social capital (Bohn et al., 2014) and increases loneliness (Stepanikova et al., 2010; Teppers et al., 2014), and how online social exclusion can cause feelings of cyberostracism (Williams et al., 2000; Tobin et al., 2015). The findings discussed herein imply that while social media users may experience enhanced feelings of social connectedness, some may be exposing themselves to potential negative outcomes. As such, the social outcomes of social media use are not always clear.

Based on the literature presented here, it seems that the direction of social connectedness outcomes associated with social media use may be contingent upon how the media are used (i.e., regular vs. intensive). For example, regular social media usage appears to be useful for enhancing offline social connectedness by increasing social capital (Ellison et al., 2007; Steinfield et al., 2008; Vitak et al., 2011) and reducing loneliness (Große Deters \& Mehl, 2013; Lou et al., 2012). These findings support the social augmentation hypothesis formulated by Ahn and Shin (2013), a notion that was initially derived from research based on older forms of online communication (i.e., email, chat rooms). Ai (2013) states that online communication provides a supplement for more traditional methods of communication, which can lead to enhanced connectedness.

However, as a counterpoint to this argument, this article presents evidence that excessive social media use (e.g., adding vast numbers of friends or excessive posting on SNSs) may reduce the benefits received from close relationships (Bohn et al. 2014) and increase loneliness (Stepanikova et al., 2010; Teppers et al., 2014). This idea, known as the displacement hypothesis (Ahn \& Shin, 2013), argues that time spent socialising on the internet detracts from beneficial offline social encounters and has deleterious effects on psychological wellbeing (Valkenburg \& Peter, 2007).

There is also emerging evidence to suggest that the individual characteristics of social media users may influence the direction of social outcomes. Research based on older forms of computer-mediated communication suggests that socially anxious people benefit from their online interactions due to online disinhibition (Suler, 2005), a phenomenon known as the social compensation hypothesis (Desjarlais \& Willoughby, 2010; Jin, 2013; Poley \& Luo, 2012). However, the results discussed here suggest that shy or socially anxious individuals who use social media to achieve online disinhibition may actually be at risk of increasing their loneliness (Teppers et al.,
2014). Such outcomes suggest that the social compensation hypothesis may need to be revised to account for the effects of social media use.

\section{Limitations and Future Research}

Because the study of social media use and social connectedness is still in its infancy, our review of articles is smaller than what may be expected of a domain with longstanding empirical research. Greater empirical accounts of social media use and connectedness will make it possible to disaggregate findings by social media type. By doing so, researchers will be better positioned to answer pressing questions regarding the nature of participants' experiences on these different sites. For example, Facebook encourages users to present their real identities online (i.e., by using their actual names and faces), and Facebook Friends lists usually comprise a high percentage of real-life contacts and acquaintances. As a result, socially anxious internet users may fail to achieve social compensation by using Facebook, as this medium does not provide them with the same sense of anonymity that older forms of online social communication would have. Instead, these types of people may prefer to use forms of social media where anonymity is more widely accepted (e.g., Twitter, Tumblr). It is our hope that a larger body of empirical studies will provide answers to this and similar questions in years to come.

It is also worth noting that research relating to social media use has traditionally focused on a narrow demographic (i.e., undergraduate students). Previously, scholars have noted that this may have been due to the fact that popular forms of social media (e.g., Facebook) were initially designed with university students in mind (Ryan \& Xenos, 2011). Unfortunately, this overwhelming reliance on student samples remains a substantial limitation in this field, and one that should be addressed by broadening the age range for further studies. Doing so would enhance understanding of the interplay between social connectedness and social media use across the lifespan.

While the studies presented in this article were not exhaustive, this brief overview of the relation between social connectedness and social media use supports previous research (e.g., Ahn \& Shin, 2013; Allen et al., 2014; Grieve et al., 2013; Sheldon et al., 2011) and raises new questions for theory and application. Considering that frequent social media use is associated with both adaptive and maladaptive outcomes in correlational research, designs that provide more definitive and systematic depictions of these relationships also may be helpful. For example, more studies that randomly assign individuals, such as a group of incoming college freshmen, to various conditions of social media use would provide clear insights regarding how specific populations negotiate connections with others. In addition, it is recommended that researchers carefully design empirical studies 
in order to directly examine whether certain factors (e.g., level of use, personality traits, age) mediate the direction of social connectedness outcomes from social media use.

Of course, it is understandable that not all types of examinations lend themselves to applied experimental designs. Therefore, a preliminary step may be to conduct laboratory-based research in which individuals navigate unfamiliar social territories - perhaps providing one group with access to a social media site in order to aid them in establishing such connections. Studies such as these enhance the causal inferences researchers are able to make regarding social media use, face-to-face communications, and patterns of social connectedness.

Another future research direction concerns the individual and situational factors that may enhance or undermine the effects of social media use on perceptions of connectedness. Prior research suggests that people vary in their need to belong (Leary, Kelly, Cottrell, \& Schreindorfer, 2013), their willingness to communicate (McCroskey, 1992), their rejection sensitivity (Downey $\&$ Feldman, 1996), and social anxiety (La Greca \& Lopez, 1998). These individual difference characteristics may cause users to ascribe very different meanings to the same experience. For example, a person who has a strong need to belong despises the idea of being alone and can be easily hurt when they are excluded from groups. Given that 'likes' or comments on social media can be construed as a public display of the enjoyment a person brings to others, receiving a high volume of such feedback on posted content may have an especially positive impact on such individuals' overall dispositions and perceptions of connectedness. On the other hand, failure to receive any feedback on posted content may lead to a sense of social exclusion or rejection. Overall, studies that either employ developmental and experimental techniques, or examine specific situational and individual contingencies, provide a more fine-grained approach to understanding the linkages between social media use and social connectedness.

Lastly, new social media applications offer features that have not historically been available, which raises questions regarding how their use affects perceptions of connectedness among both the general public and specific users. For example, Snapchat allows users to send and receive pictures and short videos that will self-destruct after the recipient has viewed them. This application also alerts the sender if recipients take a screenshot of their photo in an attempt to save a copy of it for later personal viewing. These unique features may do more than attract new users; they may also provide new mechanisms for being open and honest with specific message recipients through what is referred to as direct messaging. Moreover, individuals who are among the first to join these new forms of social media may seek specific gratifications, and obtain social connectedness, in ways that differ from individuals who join at a later time. A more fine-grained approach is therefore important for understanding the implications of novel social media platforms, and the benefits of using specific features.

\section{General Conclusions}

This article presents a narrative literature review in which the outcomes of social media use were examined, specifically with regard to three domains of social connectedness: social capital, sense of community, and loneliness. In each domain, studies revealed that social media use has both positive and negative potentiality. So far, it appears that whether social media use enhances social connectedness or diminishes it is dependent on who is engaging with it and how they choose to use it. At this stage, further confirmatory research is recommended to consolidate these arguments and to explore the relevance of existing theory to different subgroups of social media users.

New forms of social media continue to change not only the way we share knowledge and communicate but also how we socially connect with others. Thus, the future is bright for research investigating how rapid changes in online technologies are influencing our social interactions, and in turn, how we define and experience belonging, community, and advancement. Given the prevalence of social media in our daily lives, studying the capacity of these sites to foster social connectedness has never been more important.

\section{Acknowledgments}

The authors wish to acknowledge Dr Terence V. Bowles at the Melbourne Graduate School of Education, The University of Melbourne for early editing assistance on the first 1,000 words of this paper.

\section{Disclosure Statement}

No financial support was received for this study, and no competing financial interests exist.

\section{References}

Ahn, D., \& Shin, D. (2013). Is the social use of media for seeking connectedness or for avoiding social isolation? Mechanisms underlying media use and subjective well-being. Computers in Human Behaviour, 29, 2453-2462.

Ai, M. (2013). How computers and internet use influences mental health: A five-wave latent growth model. Asian Journal of Communication, 23, 175-190.

Allen, K.A., Ryan, T., Gray, D.L., McInerney, D.M., \& Waters, L. (2014). Social media use and social connectedness in adolescents: The positives and the pitfalls. The Australian Educational and Developmental Psychologist, 31, 18-31.

Amichai-Hamburger, Y., \& Ben-Artzi, E. (2003). Loneliness and internet use. Computers in Human Behaviour, 19, 71-80.

Bargh, J.A., McKenna, K.Y.A., \& Fitzsimons, G.M. (2002). Can you see the real me? Activation and expression of the 'true 
self on the internet. The Journal of Social Issues, 58, 3348.

Bandiera, O., Barankay, I., \& Rasul, I. (2008). Social capital in the workplace: Evidence on its formation and consequences. Labour Economics, 15, 724-748.

Baumeister, R.F. \& Leary, M.R. (1995). The need to belong: Desire for interpersonal attachments as a fundamental human motivation. Psychological Bulletin, 117, 497-529.

Blanchard, A.L., \& Markus, M. (2004). The experienced 'sense' of a virtual community: Characteristics and processes. Databases for Advances in Information Systems, 35, 65-79.

Bohn, A, Buchta, C, Hornik, K., \& Mair, P. (2014). Making friends and communicating on Facebook: Implications for the access to social capital. Social Networks, 37, 29-41.

boyd, d., \& Ellison, N.B. (2007). Social network sites: Definition, history, and scholarship. Journal of Computer-Mediated Communication, 13, 210-230.

Caplan, S.E. (2006). A social skill account of problematic internet use. Journal of Communication, 55, 721-736.

Coleman, J.S. (1988). Social capital in the creation of human capital [Supplemental material]. The American Journal of Sociology, 94, S95-S120.

Cornwell, B., Laumann, E.O., \& Schumm, L.P. (2008). The social connectedness of older adults: A national profile. American Sociological Review, 73, 185-203.

Desjarlais, M., \& Willoughby, T. (2010). A longitudinal study of the relation between adolescent boys' and girls' computer use with friends and friendship quality: Support for the social compensation or the rich-get-richer hypothesis? Computers in Human Behaviour, 26, 896-905.

Downey, G., \& Feldman, S. (1996). Implications of rejection sensitivity for intimate relationships. Journal of Personality and Social Psychology, 70, 1327-1343.

Ellison, N.B., Steinfield, C., \& Lampe, C. (2007). The benefits of Facebook 'friends': Social capital and college students' use of online social network sites. Journal of Computer-Mediated Communication, 12, 1143-1168.

Facebook. (2016, September). Stats. Retrieved from www. newsroom.fb.com/company-info.

Green, B.N., Johnson, C.D., \& Adams, A. (2001). Writing narrative literature reviews for peer-reviewed journals: Secrets of the trade. Journal of Sports Chiropractic and Rehabilitation, 15, 5-19.

Grieve, R., Indian, M., Witteveen, K., Tolan, G.A., \& Marrington, J. (2013). Face-to-face or Facebook: Can social connectedness be derived online? Computers in Human Behaviour, 29, 604-609.

große Deters, F., \& Mehl, M.R. (2013). Does posting Facebook status updates increase or decrease loneliness? An online social networking experiment. Social Psychological and Personality Science, 4, 579-586.

Gruzd, A., Wellman, B., \& Takhteyev, Y. (2011). Imagining Twitter as an imagined community. American Behavioural Scientist, 55, $1294-1318$.

Hart, M. (2011). A study on the motives of high school and undergraduate college students for using the social network site Facebook (Doctoral dissertation). Available from ProQuest Dissertations and Theses database. (UMI No. 3439733)

Henderson, M., Snyder, I., \& Beale, D. (2013). Social media for collaborative learning: A review of school literature. Australian Educational Computing, 28, 1-15.
Holladay, S., Crutcher, K., Gustavson, K., Jones, J., Laughlin, L., \& McKown, S. (1997). Older adults' motives for mediated interpersonal communication: An examination of telephone communication and loneliness. Communication Reports, 10, 173183

Jin, B. (2013). How lonely people use and perceive Facebook. Computers in Human Behaviour, 29, 2463-2470.

La Greca, A.M., \& Lopez, N. (1998). Social anxiety among adolescents: Linkages with peer relations and friendships. Journal of Abnormal Child Psychology, 26, 83-94.

Leary, M.R., Kelly, K.M., Cottrell, C.A., \& Schreindorfer, L.S. (2013). Individual differences in the need to belong: Mapping the nomological network. Journal of Personality Assessment, 95, 610-624.

Lee, Z.W., Cheung, C.M.K., \& Thadani, D.R. (2012). An investigation into the problematic use of Facebook. Proceedings of the 45th Hawaii International Conference on System Sciences, 1768 1776. doi:10.1109/HICSS.2012.106

Lou, L.L., Yan, Z., Nickerson, A., \& McMorris, R. (2012). An examination of the reciprocal relationship of loneliness and Facebook use among first-year college students. Journal of Educational Computing Research, 46, 105-117.

McCoy, J.A. (1999). The influence of social connectedness on anxiety and self-esteem under conditions of stress. Journal of Counseling Psychology, 45, 338-345.

Malta, S. (2005, December). Social connectedness and health amongst older adults. Paper presented at TASA Conference, Tasmania, Australia.

Mauss, I.B., Shallcross, A.J., Troy, A.S., John, O.P., Ferrer, E., Wilhelm, F.H., \& Gross, J.J. (2011). Don't hide your happiness! Positive emotion dissociation, social connectedness, and psychological functioning. Journal of Personality and Social Psychology, 100, 738-748.

McCroskey, J.C. (1992). Reliability and validity of the Willingness to Communicate Scale. Communication Quarterly, 40, $16-25$.

Papacharissi, Z., \& Mendelson, A. (2011). Toward a new(er) sociability: Uses, gratifications and social capital on Facebook. In S. Papathanassopoulos (Ed.), Media perspectives for the 21st century (pp. 212-230). London, UK: Routledge.

Poley, M.E., \& Luo, S. (2012). Social compensation or rich-getricher? The role of social competence in college students' use of the internet to find a partner. Computers in Human Behaviour, 28, 414-419.

Pretty, G.M., Conroy, C., Dugay, J., Fowler, K., \& Williams, D. (1996). Sense of community and its relevance to adolescents of all ages. Journal of Community Psychology, 24, 365379 .

Putnam, R.D. (2000). Bowling alone: The collapse and revival of American Community. New York, NY: Simon \& Schuster.

Reich, S.M. (2010). Adolescents' sense of community on MySpace and Facebook: A mixed-methods approach. Journal of Community Psychology, 38, 688-705.

Russell, D. (1996). The UCLA loneliness scale (Version 3): Reliability, validity, and factor structure. Journal of Personality Assessment 1996; 66, 20-40.

Ryan, T., \& Xenos, S. (2011). Who uses Facebook? An investigation into the relationship between the Big Five, shyness, narcissism, loneliness and Facebook usage. Computers in Human Behaviour, 27, 1658-1664. 
Saunders, P.L., \& Chester, A. (2008). Shyness and the internet: Social problem or panacea? Computers in Human Behaviour, 24, 2649-2658.

Sensis. (2016). Sensis social media report 2016. Retrieved from https://www.sensis.com.au/assets/PDFdirectory/Sensis_ Social_Media_Report_2016.PDF

Sheldon, K.M., Abad, N., \& Hinsch, C. A. (2011). Two-process view of Facebook use and relatedness need-satisfaction: Disconnection drives use, and connection rewards it. Journal of Personality and Social Psychology, 100, 766-775.

Stebbins, R.A. (2001). Exploratory research in the social sciences. Thousand Oaks, CA: Sage Publications.

Spiliotopoulos, T., \& Oakley, I. (2013, April-May). Understanding motivations for Facebook use: Usage metrics, network structure, and privacy. Paper presented at CHI, Paris, France.

Steinfield, C., Ellison, N.B., \& Lampe, C. (2008). Social capital, self-esteem, and use of online social network sites: A longitudinal analysis. Journal of Applied Developmental Psychology, 29, 434445.

Stepanikova, I., Nie, N.H., \& He, X. (2010). Time on the internet at home, loneliness, and life satisfaction: Evidence from panel time-diary data. Computers in Human Behaviour, 26, 329-338.

Sum, S., Mathews, R.M., Pourghasem, M., \& Hughes, I. (2009). Internet use as a predictor of sense of community in older people. CyberPsychology \& Behaviour, 12, 235-9.

Suler, J. (2005). The online disinhibition effect. International Journal of Applied Psychoanalytic Studies, 2, 184-188.

Teppers, E., Luyckx, K., Klimstra, T.A., \& Goossens, L. (2014). Loneliness and Facebook motives in adolescence: A longitudinal inquiry into directionality of effect. Journal of Adolescence, 37, 691-699.

Tobin, S.J., Vanman, E.J., Verreynne, M., \& Saeri, A.K. (2015). Threats to belonging on Facebook: Lurking and ostracism. Social Influence, 10, 31-42

Turkle, S. (2011) Alone together: Why We expect more from technology and less from each other. Philadelphia, PA: Basic Books.

Valkenburg, P.M., \& Peter, J. (2007). Online communication and adolescent well-being: Testing the stimulation versus the displacement hypothesis. Journal of Computer-Mediated Communication, 12, 1169-1182.

van Bel, D., Smolders, K., Ijsselsteijn, W., \& De Kort, Y. (2009). Social connectedness: Concept and measurement. In V. Callaghan, A. Kameas, A. Reyes, D. Royo, \& M. Weber (Eds.), Proceedings of the 5th International Conference on Intelligent Environments (pp. 67-74). Amsterdam, the Netherlands: IOS Press.

van Bel, D., Smolders, K., Ijsselsteijn, W., \& de Kort, Y. (2011, July). Great minds think alike: I-sharing promotes social connectedness. Paper presented at the European Association for Social Psychology, Stockholm, Sweden.

Vitak, J, Ellison, N.B., \& Steinfield, C. (2011). The ties that bond: Re-examining the relationship between Facebook use and bonding social capital. In Proceedings of the 44th Hawaii International Conference on System Sciences (pp. 1-10). Kauai, HI: Computer Science Press.

Williams, K.D., Cheung, C.K., \& Choi, W. (2000). Cyberostracism: Effects of being ignored over the internet. Social Psychology, 79, 748-762. 